\title{
The Implementation Path of Funding for Education in Colleges and Universities in Computer Age
}

\author{
Gui Wei ${ }^{1}$, Zhang Jianrong ${ }^{2}$, Zhong Wenbin ${ }^{3^{*}}$ \\ ${ }^{1}$ School of Humanities, Jiangxi University of Traditional Chinese Medicine, 818 Meiling Road, \\ Nanchang 330004, Jiangxi, P.R. China; \\ 2. Jiangxi Institute of Fashion Technology,Nanchang City in Jiangxi Province to the pond li lake road \\ of Economic Development Zone \\ 3.School of Computing, Jiangxi University of Traditional Chinese Medicine, 818 Meiling Road, \\ Nanchang 330004, Jiangxi, P.R. China;
}

*Corresponding author: Zhong Wenbin .Email:328759165@qq.com

Keywords: Computer age; Colleges and universities; Funding; Education; Path selection

\begin{abstract}
With the advent of computer age, college education mode is constantly changing. Impoverished students' funding has higher requirements with the advent of the new era. This article explores university funding work implementation path through analyzing impoverished students' characteristics in computer age and innovating funding and educating way.

In information age, teenagers use computers more. For impoverished college students growing in computer age, there are differences between the individuals and there are new problems. Adolescent behavior is deeply affected by the network in the era. In computer age, we should conform to the times, fully understand impoverished undergraduates' needs for reality and the characteristics of the students under the new era. Make good use of network innovative thinking funding and educating work in the era of computer and better help impoverished students.
\end{abstract}

\section{New characteristics of college students in computer age}

\section{Concept and behavior under the influence of network culture.}

Under the influence of the Internet era, impoverished students' thought and behavior are impacted greatly. In mainstream network influence, impoverished students form an emotional expression, behavior habit and value orientations accepted by social identity and develop in the direction of individual socialization. In open mode information age, money worship and consumerism and enjoyment thoughts arise along with poverty gap. Under the influence of these thoughts, students also begin to produce the social mainstream misunderstanding and suspicion. The forces like mainstream crowds' value orientation and values identity and ideological conflict caused by poverty affect the impoverished students' fresh values and behavior norms. Under the influence of these ideas, ideas and behaviors of the impoverished freshmen begin to blend in mainstream values or be marginalized by the mainstream. In varied modernization, ideas are intertwined and some impoverished students are still under the influence of socialist core idea, but there are some extreme people.

Affected by the Internet age, modern college students' thoughts are more open. They like to make public individual character, like different, do not blindly follow trends, like personalized tag, love to express themselves and hope to get other people's attention and recognition. And impoverished students like using computer network technology. They show their ego in the Internet of equality, secretiveness and openness, play any role on the Internet without thinking about secular factors such as status, wealth, status, appearance, and expect to get the recognition and attention of others by their performance. They are full of curiosity about new things and are easy affected by the novelty. I like to participate in a variety of innovative activities and like to use some crossover ideas to solve life problems. 


\section{Pay special attention to the satisfaction of individual needs.}

For funding problems of impoverished students, students care about equity financing. Students prefer using computer network technology, such as certain new media like websites or Weibo, to know about funding problems and like to share some fresh things with their classmates. At the same time, they also focus on funding allocation through the network, funds evaluation conditions, or the fairness of the evaluation process, etc. On funding, students still want to wait for unique and comprehensive measures which not only include good and very impoverished students, but also want a mediocre but impoverished people; On conditions, students still want fully consideration of the impoverished students' situation and give some conditions limit to prevent false impoverished students; Impoverished evaluation process should be on some simple convenient network platform, but it should have a complete comprehensive evaluation requirements and specifications, and complete and fair assessment procedures, and have good feedback. These guarantee the authenticity of fair evaluation. In addition, some volunteers with a sense of fair play can be chosen to monitor network evaluation.

Students' psychology needs special attention, especially impoverished students. They prefer to get heart guidance. Lack of material is the root causing impoverishment, but lack of correct guidance may influence the impoverished students' psychological health. Thus, impoverished students spiritual support is very important. Comprehensive and detailed help and guidance for impoverished students is beneficial to their physical and mental health development. First, give psychological, economy, ideology and overall support services, and the most important still is the mind guidance, employment assistance, etc., and family relatives and friends' caring can help them grow healthily.

In the era of computer network technology, free, open and fair network culture is popular with those college students with subject consciousness and independent awareness. Therefore, network has become the important platform for impoverished students to show ego and highlight their selfworth. They focus on media news, issue personal view and participate in various social activities through the network platform. They like to express themselves loosely in the virtual world, and put all the happy or unhappy things on the Internet. Portable phone AAP is very popular with the students, and they will put a lot of time and energy in WeChat, Weibo and other social networking platforms. They expand their circle of friends through this way. Also, they like to use various social resources to carry out social practice activity.

\section{Impoverished students' psychological characteristics and differences.}

There are many differences between impoverished students, such as geographical differences, gender differences, grade differences, etc. Financial help still cannot solve psychological problem. On communication issues, impoverished students are passive; but on gratitude consciousness, rural impoverished students are more gratitude than urban impoverished students, and junior students have more gratitude consciousness than that of senior students. For senior students, employment problem is a problem. Facing the present employment situation, senior students' employment pressure is increasing. Many impoverished students like to eliminate their pressure through network channels. Many students like using the Internet for entertainment and network become an important way of relieving stress. They ease mood, place their feelings, kill time, etc. through a variety of online entertainment functions. Especially now wireless network coverage and the popularity of school wireless network strengthen the students' interest in the Internet. This brings upside for impoverished students, balancing the psychological damage in real life because of the gap between rich and impoverished and different identities.

\section{The new requirements for poverty funding for education work in computer age}

Focus on the characteristics of impoverished students in network era.

With the advent of computer era, network culture is widely spread, and college students' network thought is gradually formed. Impoverished students also begin to use computers. With the use of computer network technology, they pursue convenient, free, and sharing information resources; Demand for funding for education, they hope to have more comprehensive and 
hierarchical scheme and better to ensure privacy; According to the present college students' dependence of the network, we can see that students expand at a several times speed in the network society's personal space between virtual and reality. Therefore, only fully understand the needs of the impoverished students and the real Times characteristics of impoverished students can we better grasp the real situation of impoverished students and do good work in funded education and achieve the goal of funding for education.

\section{Make good use of the computer age product review blind spot.}

In the current era of information technology, funding for education still has some problems. Finance function development still exists economic benefits and the purpose of education is not clear; some impoverished students began to produce negative dependence psychology and lack gratitude consciousness, lose integrity awareness, and then begin to appear competition abnormality in poverty; this leads to pseudo poverty phenomenon and welfare superposition phenomenon, which makes the financing of education idea goes downhill; this bias operation mechanism and single static feedback mechanism greatly reduces the function of funding for education; Publicity channels occlusion, the limitation of funding sources and the sheer level of funding for education platform will weaken funding for educational work. So, computer network thought is used to review funding for educational work, find out the blind spot, suit the remedy to the case, and work for the sustainable development of funding for educational work. For impoverished students' new era characteristics, make use of computer network technology and network thinking, make effective reform on the management of students and funding system, constantly improve implementation means of funding for educational work, and enhance the working efficiency of funding for education.

\section{The realization path of funding for educational work in computer age}

\section{Establish funding for education work according to the provisions of the state.}

Our country's "All-round implementation of lawful requirements outline" asks for colleges and universities should have operations in accordance with law consciousness, and at the same time, teachers also should do their duty. To continue college funding for educational work development, law guarantees that be carried out orderly. The premise of funding for education is to guarantee the legitimate rights and interests of students, fully respect students' individual rights; ensure that integration, comprehensive and integrity of funding for education is to build funding for education with the rule of law spirit. And teachers should be example and improve the students' rule of law consciousness and noble personality charm.

\section{Realize funding for education from impoverished students point of view.}

The funding for education work mainly depends on education and funding is only an aid. And funding for education work's main object is impoverished students. Therefore, we must have target object thinking, adhere to "people-oriented" education philosophy, and provide better service to cultivate, educate, and serve the impoverished students who need funds. First, school should make good use of the existing resources to better play educational work philosophy. While giving financial aid, play good education work idea and guide the students to be men with full positive energy. Guide the awareness of right from wrong and pay attention to the healthy comprehensive development of impoverished students. In addition, we should have impoverished students' subjective consciousness. From their point of view, fully grasp the actual needs of the impoverished students and ensure the efficiency of funding work. So, carry out some practical activities for impoverished students, or establish public platform in response to social boom. Give abundant opportunities for impoverished students to show themselves and offer a lot of help for their healthy psychology.

Make good use of the product of computer age and innovate funding for education path.

Funding for education work is a long-term work with a large scope of personnel. Therefore, establish database by computer for better reform and management. Build funding for education web site on the Internet to establish detailed financing functions such as application condition, quota restrictions, selection process, and funding requirements, and realize online application and 
approval. Form database by impoverished students' application and collect impoverished personnel data for data statistics. For impoverished students, government or public sector can check the students' family and personal information online and give correct judgment. This is better to dock with colleges and universities and set up detailed information for impoverished data. Furthermore, relevant departments can make accurate analysis of the funding for education according to the big data, predict the development funding for education in the future by impoverished students' characteristics with the Times change, combined with the reality demand of impoverished students and formulate reasonable funding for educational policy; regularly carry out some impoverished students' funding requirements, feedback, satisfaction survey, etc., continuously improve education strategy, and finally complete the ultimate goal of funding for education.

\section{Conclusion}

According to the analysis, computer generalization accelerates the development of the various aspects of society. The formation of network culture constantly affects modern impoverished freshmen's thoughts and behavior. To make impoverished students establish good values and correct awareness of right from wrong and promote the healthy development of the impoverished students, we should have the idea of keeping pace with The Times; make good use of computer network technology resources to give impoverished students better service and help. In today's computer age, colleges and universities are facing the challenge of new funding for education strategy. Therefore, school should make good use of the resources of computer network era have entrusted to on the premise of lawful management, set up a network thinking mode funding for educational work, build complete education system by a good way and realize the ultimate goal of funding for education.

\section{References}

[1] Cai Ying, Xu Zhimin, Zhong Huina, Zhao Chuhong. The implementation mechanism and path selection of university funding for education work under Internet thinking [J]. Journal of Coal Higher Education, 2016,01:59-63.

[2] Song Jia, Xu Dandan. University funding for education work path exploration under network background [J]. Journal of Jiamusi Vocational College, 2016, 06: $286+288$.

[3] Fan Xiaoting. College fund management review research [D]. Beijing University of Science and Technology, 2016.

[4] Xia Boyi. The moral function research of university funding for education work [D]. Central China Normal University, 2015.

[5] Yang Yaxing. Students with financial difficulties funding policy research in colleges and universities [D]. East China Normal University, 2013. 